\title{
Anatomia óssea e muscular da coxa de Tapirus terrestris (Perissodactyla, Taperidae)*
}

\section{Bone and muscular anatomy of the thigh leg of Tapirus terrestris (Perissodactyla, Taperidae)}

\author{
Daniela Cristina Silva Borges, ${ }^{* *}$ Saulo Gonçalves Pereira, ${ }^{* * *}$ Rogério Rodrigues de Souza, ${ }^{* *}$ José Onício Rosa da Silva, ${ }^{* *}$ \\ André Luiz Quagliatto Santos***
}

\begin{abstract}
Resumo
Tapirus terrestris (Linnaeus, 1758) é conhecida como anta brasileira é um mamífero da ordem Perissodactyla, o único dessa ordem que ocorre de forma endêmica no Brasil, sendo considerado maior mamífero brasileiro. Existem poucos estudos relacionados à sua morfologia. Objetivou-se descrever os ossos e os músculos da coxa de T. terrestris. Foram utilizados quatro exemplares de $T$. terrestris fixados em formaldeído a 10\%. Para a descrição osteológica, os ossos foram macerados, limpos e secos, identificados e descritos. Para a descrição muscular, os músculos foram dissecados, segundo as técnicas usuais em anatomia macroscópica. O esqueleto da região glútea de $T$. terrestris é constituído pelo osso do quadril, a coxa é constituída e pelo osso fêmur.. Os músculos (M.) que compõe a coxa são o M. Tensor da fáscia lata, M. Bíceps femoral, M. Semitendíneo, M. Semimembranáceo, M. Grácil, M. Pectíneo, M. Quadríceps femoral, M. Adutor, M. Sartório, M. quadrado profundo, M. piriforme, M. gêmeos e M. obturador interno. Conclui-se que $T$. terrestris possuem características osteológicas e musculares semelhantes a dos equinos, Entretanto, algumas diferenças morfológicas são evidenciadas.
\end{abstract}

Palavras-chave: Morfologia, Osteologia, Miologia, Anta.

\begin{abstract}
The species Tapirus terrestris (Linnaeus, 1758) is known as Brazilian tapir is a mammal of the order Perissodactyla, the only order that which occurs endemic in Brazil, considered largest mammal Brazilian. There are few studies related to their morphology. The study aimed to describe the bones and muscles of the thigh T. terrestris. We used four specimens of T. terrestris fixed in $3.7 \%$ formaldehyde. For osteological description, the bones were macerated, cleaned and dried, identified and described. For a description of muscle, the muscles were dissected according to the usual techniques in gross anatomy. For the histological description samples were collected every muscle they have been processed and applied stains hematoxylin and eosin, Masson's trichrome, and Orcein Reticulin, followed by analysis by light microscopy. The skeleton of the gluteal region of T.s terrestris consists of hip bone, thigh bone that is formed by the femur. The muscles (M.) that makes up the thigh are M. Tensor fascia lata, M. Biceps femoris, M. Semitendinosus, M. Semimembranosus, M. Gracilis, M. Pectineus, M. Quadriceps femoris, M. Adductor,M. Sartorius and M. quadratus profundus, M. piriformis, M. gemelis e M. obturator internus. Histologically muscles showed striated muscle fibers, collagen fibers, elastic and reticular fibers. We conclude that the T. terrestris have characteristics similar to osteological and muscle of horses, however, some differences were evident fact that can be corroborated by locomotor patterns acquired by the species due to its habitat.
\end{abstract}

Keywords: Morphology, Osteology, Myology, Tapir.

\section{Introdução}

Os ungulados são compostos pelas ordens Artiodactyla e Perissodactyla. As características principais dos ungulados são as estruturas dos membros, onde os ossos metapodiais são fundidos formando uma única estrutura, geralmente apresentam uma redução no número de dedos (Borges et al., 2016). Os Perissodactylas apresentam cascos e dedos ímpares, com cascos córneos em todos os dedos (Hickman et al., 2009; Pereira et al., 2015).
Segundo Padilla e Dowler (1994) e Pereira et al., (2017a) a anta é considerada um ungulado e são registradas apenas cinco espécies de antas ( T. bairdii - Gill -1865, T. indicus - Desmarest, 1819, T. pinchaque - Roulin, 1829, T. terrestris - Linnaeus, 1758 e T. kabomani - Cozzuol, 2013) tais espécies são classificadas na Ordem Perissodactyla, Subordem Ceratomorpha, Superfamília Tapiroides, Família Tapiridae e Gênero Tapirus.

A espécie T. terrestris, também conhecida como anta brasileira, é considerada como o maior mamífero terrestre da América

${ }^{*}$ Recebido em 30 de setembro de 2018 e aceito em 1 de dezembro de 2018.

**Laboratório de Ensino e Pesquisa em Animais Silvestres (LAPAS); Universidade Federal de Uberlândia (UFU). Faculdade Cidade de João Pinheiro.

***Laboratório de Ensino e Pesquisa em Animais Silvestres (LAPAS); FAMEV. Universidade Federal de Uberlândia - UFU.

**** Laboratório de Ensino e Pesquisa em Animais Silvestres (LAPAS); Universidade Federal de Uberlândia (UFU). Faculdade Patos de Minas.

Autora correspondente: danybio@hotmail.com 
do Sul. Ela possui uma ampla distribuição geográfica que vai desde a América do Sul a leste dos Andes, desde a Venezuela até o nordeste da Argentina e Paraguai (Padilla e Dowler, 1994; Medici, 2011; Pereira et al. 2017b). Esta espécie desempenha um papel fundamental como dispersora de grandes sementes controlando a manutenção de espécies vegetais (Salas, 1996). Segundo Pereira et al., (2015) os T. terrestris tem a capacidade de se locomoverem por grandes distâncias sendo adaptados a ambientes terrestres e aquáticos.

Dessa forma, com o intuito de fornecer mais dados anatômicos sobre a espécie, o presente trabalho teve por objetivo descrever os ossos e músculos da coxa de T. terrestris com ênfase em suas origens, inserções e ações.

\section{Material e métodos}

Foram utilizados quatro exemplares de T. terrestris pertencentes ao acervo didático-científico do Laboratório de Ensino e Pesquisa em Animais Silvestres, da Universidade Federal de Uberlândia (LAPAS-UFU). Os espécimes foram fixados em solução aquosa de formaldeído a $10 \%$ e conservados em cubas opacas contendo a mesma solução.

Para a descrição dos ossos três espécimes foram macerados em água fervente e posteriormente colocados em solução de peróxido de hidrogênio. Depois de limpos e secos, os ossos foram identificados e minuciosamente descritos. Já para a descrição muscular onde inicialmente foi feita a retirada da pele e do excesso de tecido adiposo, os músculos foram expostos e dissecados, segundo as técnicas usuais em anatomia macroscópica, observando-se a origem, inserção e distribuição muscular.

A descrição tanto óssea quanto muscular foi baseada e comparada com dados existentes na literatura, sendo que a nomenclatura adotada para esta pesquisa está de acordo com o International Committee on Veterinary Gross Anatomical Nomenclature (2012 e 2017). As imagens foram registradas com câmera digital e as fotos foram editadas pelo software Photoshop CS (2012 @). O procedimento foi aprovado pela comissão de ética na utilização de animais sob protocolo de registro $n^{\circ} 069 / 12$, e está de acordo com a Instrução Normativa 154/2007 do IBAMA.

\section{Resultados e discussão}

Ossos do membro pelvino: $O$ membro pelvino de $T$. terrestris constitui-se em quatro segmentos, cintura pelvina (osso do quadril), coxa (fêmur), perna (tíbia e fíbula) e pé (tarso, metatarso e dedos).

O quadril é formado por três ossos, ílio, ísquio e púbis, conforme mostra a Figura 1. O ílio é o mais cranial dos três ossos e encontra-se na parte cranial do quadril, é um osso irregular plano pouco triangular, apresentando duas faces. A porção mais larga do ílio denomina-se asa com duas faces, glútea (côncava) e sacropelvina (convexa) sendo rugosa articulando-se com o sacro. Ainda na asa em sua porção cranial encontra-se o tuber sacral que é uma projeção pontiaguda correspondente aos achados de Varela (2010) em Ozotoceros bezoarticus - Linnaeus, 1758 (veado-campeiro).
O tuber coxal tem aspecto retangular e localiza-se lateralmente ao sacro, no tuber coxal encontram-se duas tuberosidades, uma dorso-cranial na qual se estende em sua face medial uma espinha longitudinal e outra na porção ventro-cranial projetandose medialmente, unindo os tuberes sacral e coxal encontra-se a crista ilíaca, caudalmente ao tuber sacral encontra-se a incisura isquiática maior. O corpo do ílio é estreito e funde-se ao púbis e ao ísquio caudalmente, formando o acetábulo, que é uma cavidade arredondada e profunda que aloja a cabeça do fêmur, a superfície da cavidade acetabular apresenta uma área rugosa não articular chamada fossa do acetábulo. Segundo Oliveira (2007) a profundidade do acetábulo confere boa estabilidade coxo-femoral.

O púbis é o menor dos três ossos e forma a porção cranial do assoalho do quadril. É constituído de ramo cranial, ramo caudal e corpo. O ramo cranial liga-se ao acetábulo. O ramo caudal é menor e mais delgado que o cranial e liga-se ao ísquio, ambos unem-se no plano mediano formando a sínfise pelvina. O púbis encontra-se coberto por musculatura e tecido conjuntivo conforme os achados de Varela (2010) em Ozotoceros bezoarticus

O ísquio forma o assoalho caudal da pelve, sendo um osso irregular, achatado e retangular com corpo, tabula, ramo, tuber e incisura. O corpo une-se sem limites nítidos com o ramo do ísquio e se estende ate o acetábulo. A tabula por sua vez é a porção mais larga do ísquio. A incisura isquiática menor é uma reentrância que se estende da espinha isquiática ao tuber isquiático. Na porção dorso-lateral localiza-se uma espinha que se estende do tuber ao corpo. As bordas caudais dos ísquios formam em conjunto o arco isquiático. O forame obturado é um espaço entre o púbis e o ísquio, sendo que possui formato ovalado semelhante ao Equus caballus (cavalo) como descrito por Getty (2013).

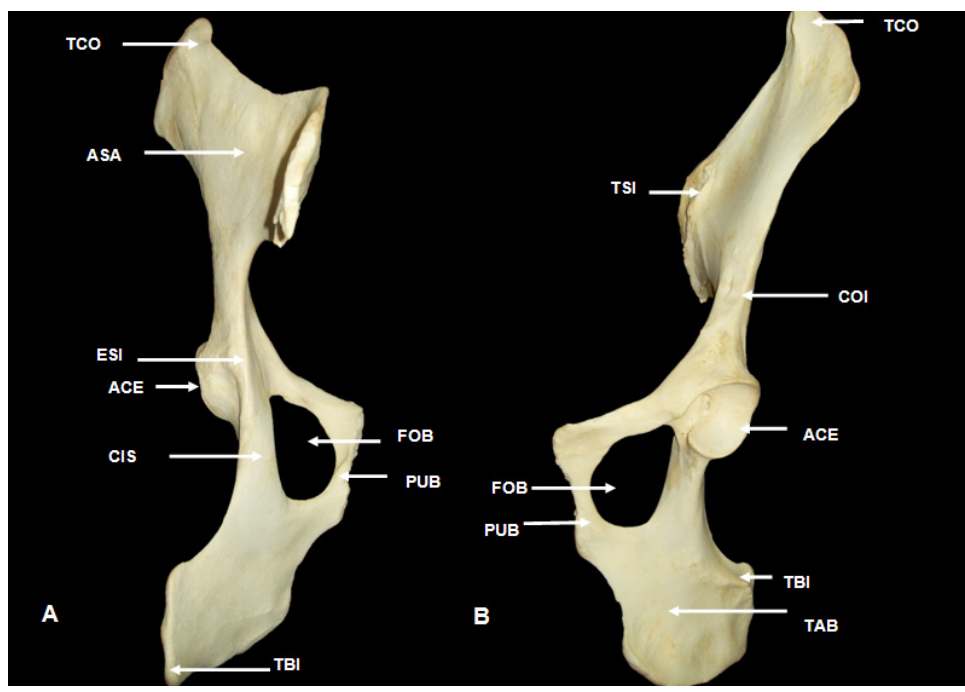

Figura 1: Fotografia do osso do quadril de Tapirus terrestris. (A), vista dorsal; (B), vista ventral. FOB, forame obturado; ACE, acetábulo; ASA, asa do ílio; TCO, tuberosidade coxal; TBI, tuberosidade isquiática; PUB , pube; ESI, espinha isquiática; CIS, corpo do ísquio; COI, corpo do ílio; TBI, tuberosidade isquiática; FOB, forame obturado; TSI, tuberosidade sacroilíaca; TAB, tabula.

O fêmur é o osso da coxa constituído de duas extremidades e um corpo, sendo um osso longo (Figura 2). A extremidade proximal consiste em: cabeça, colo e trocânteres maior e menor. 
A cabeça é uma proeminência arredondada mais extensa dorsal do que ventralmente, sua superfície articular encontra-se voltada medialmente articulando-se com o acetábulo.

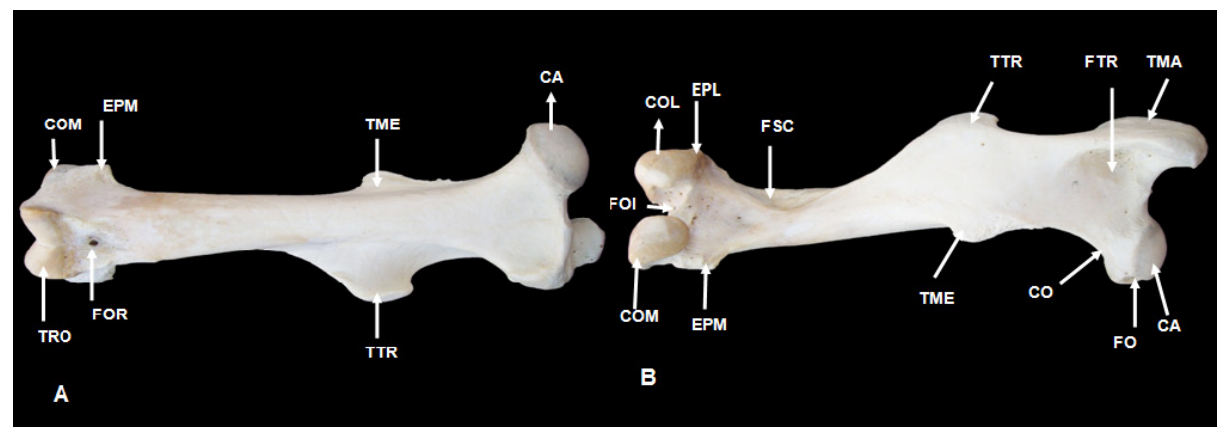

Figura 2: Fotografia do osso fêmur de Tapirus terrestris. (A), vista cranial; (B), vista caudal. TRO, tróclea; FO, forame nutrício; COM, côndilo medial; EPM, epicôndilo medial; TME, trocânter menor; TTR, terceiro trocânter; CA, cabeça; CO, colo; TME, trocânter menor; TTR, terceiro trocânter; TMA, trocânter maior; EPM, epicôndilo medial, COM, côndilo medial; COL, côndilo lateral; EPL, epicôndilo lateral; FSC, fossa supracôndilar; FTR, fossa trocânterica, FOV, fóvea; FOI, fossa intercôndilar.

A fóvea da cabeça do fêmur encontra-se na face medial obliquamente voltada para a face caudal, sendo o colo mais distinto cranial e medialmente. O trocânter maior localiza-se na face lateral na extremidade proximal do osso. Na face caudal do trocânter maior localiza-se a incisura trocantérica sendo que sua borda segue distalmente formando as paredes da fossa trocantérica.

O corpo do fêmur é cilíndrico e longo. A face caudal é larga, plana e áspera no seu quarto distal, com a presença de forames nutrícios. Lateralmente próximo ao terceiro trocânter encontra-se uma pequena elevação que serve de inserção ao tendão do músculo bíceps femoral e medialmente há uma linha rugosa onde se insere o músculo quadrado da coxa.

Na face medial na porção proximal localiza-se o trocânter menor, uma crista rugosa, pouco proeminente se comparada ao terceiro trocânter que é bem desenvolvido. A extremidade distal do fêmur é constituída pela tróclea e por dois côndilos. A tróclea é formada por duas arestas que se projetam distal e caudalmente e são separadas por um sulco. A aresta medial difere da aresta lateral por apresentar-se mais espessa que esta. A tróclea forma uma extensa face articular com a patela.

Caudalmente à tróclea encontram-se os côndilos lateral e medial separados pela fossa intercondilar, uma depressão profunda dotada de diversos forames nutrícios. O côndilo medial exibe uma face medial rugosa onde se encontra o epicôndilo medial. Já o côndilo lateral apresenta, por sua vez, uma saliência denominada epicôndilo lateral.

Segundo Holanda et al. (2011) em um estudo realizado sobre os mamíferos do quaternário os indivíduos da ordem Perissodactyla apresentam fêmur robusto para suportarem a estatura do individuo e provido de terceiro trocânter bem desenvolvido como apresentado em $T$. terrestris, fato também apresentado por Oliveira (2009) que descreve a proeminência do terceiro trocânter em Dasyprocta azarae Lichtenstein, - 1823 (cutia)
A patela é um osso sesamóide que apresenta formato que se assemelha a um triângulo. Apresenta face cranial e face articular, borda lateral e medial articulando-se com a tróclea do fêmur (Figura $3)$, sendo muito semelhante ao Equus caballus descrito por Getty (2013).

Músculos da Coxa: Os músculos da coxa de $T$. terrestris originam-se no osso do quadril e superfícies dos terços médio e proximal do fêmur e se inserem nas superfícies do fêmur, patela e tíbia. Foram identificados em vista lateral superficial (Figura 4A) os músculos tensor da fáscia lata, vasto lateral, bíceps femoral e semitendíneo; em vista medial superficial (Figura 4B) visualizou-se os músculos semimembranáceo, grácil, pectíneo, quadríceps femoral (vasto medial, reto femoral), sartório e adutor. Segundo Ribeiro (2016) A musculatura regional garante o suporte, estabilidade e locomoção do indivíduo.

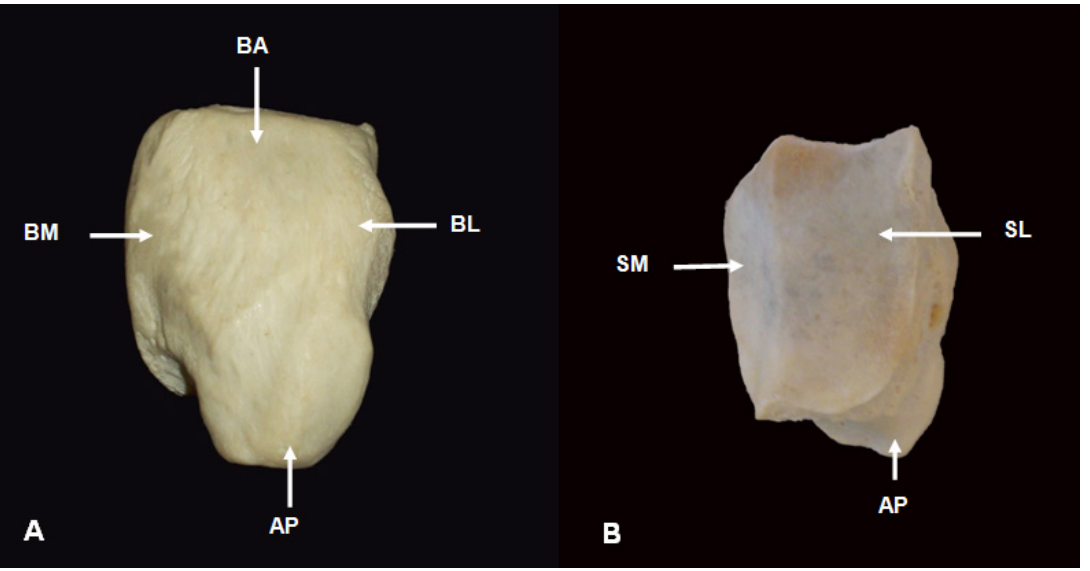

Figura 3: Fotografia da Patela de Tapirus terrestris. (A), vista cranial; (B), vista caudal. BA, borda lateral; BM, borda medial; AP, ápice; BL; borda lateral; SM, superfície medial da face caudal da patela; SL, superfície lateral da face caudal da patela.
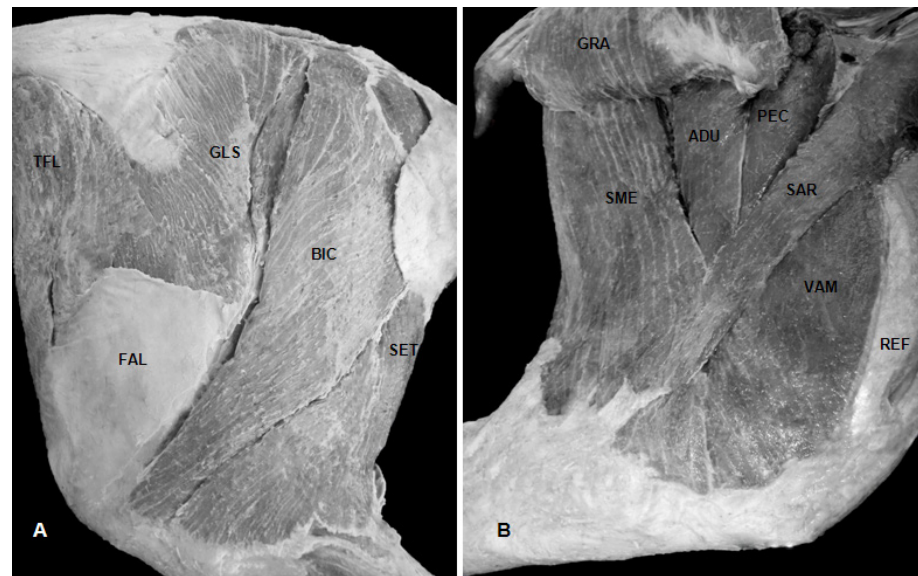

Figura 4: Fotografia dos músculos da coxa de Tapirus terrestris. (A) vista lateral superficial; (B) vista superficial medial. TFL, tensor da fáscia lata; BIC, bíceps femoral, SET, semitendíneo; FAL, fáscia lata; GLS, glúteo superficial. SME, semimembranáceo; ADU, adutor; SAR, sartório; PEC, pectíneo; VAM, vasto medial; REF, reto femoral; GRA, grácil. 
Os pontos de fixação e a ação dos músculos que compõem a coxa estão apresentados no Quadro 1. As Figuras 5, 6 e 7

mostram os pontos de origem e inserção dos músculos em questão nos ossos do membro pelvino de T. terrestris.

\begin{tabular}{|c|c|c|c|}
\hline MÚSCULO & ORIGEM & INSERÇÃO & AÇÃo \\
\hline Tensor da fáscia lata & Tuberosidade da coxa & $\begin{array}{l}\text { Ligamento patelar lateral, borda cranial } \\
\text { da tíbia e tendão do músculo reto } \\
\text { femoral. }\end{array}$ & $\begin{array}{l}\text { Tensionar a fáscia lata, flexionar a } \\
\text { articulação do quadril e estender a } \\
\text { articulação do joelho. }\end{array}$ \\
\hline Músculo bíceps femoral & $\begin{array}{l}\text { Ligamentos sacroilíacos, fáscia glútea } \\
\text { e da cauda e septo intermuscular } \\
\text { entre o bíceps semitendíneo e } \\
\text { tuberosidade isquiática. }\end{array}$ & $\begin{array}{l}\text { Eminência próxima ao terceiro trocânter, } \\
\text { superfície cranial da patela e o } \\
\text { ligamento lateral patelar, borda cranial } \\
\text { da tíbia, fáscia crural e tuberosidade } \\
\text { calcânea. }\end{array}$ & $\begin{array}{l}\text { Estender e abduzir o membro. Flexionar e } \\
\text { estender o joelho. }\end{array}$ \\
\hline Músculo semitendíneo & $\begin{array}{l}\text { Processos transversos, fáscia da } \\
\text { cauda e septo intermuscular entre } \\
\text { o semitendíneo e o bíceps femoral, } \\
\text { tuberosidade isquiática. }\end{array}$ & $\begin{array}{l}\text { Borda cranial da tíbia, fáscia crural e } \\
\text { tuberosidade calcânea. }\end{array}$ & $\begin{array}{l}\text { Estender as articulações do quadril e do } \\
\text { joelho, agindo com o músculo da coxa e o } \\
\text { músculo semimembranáceo na propulsão } \\
\text { do tronco. Flexionar o joelho e girar a } \\
\text { perna medialmente. }\end{array}$ \\
\hline Músculo semimembranáceo & $\begin{array}{l}\text { Borda caudal do ligamento } \\
\text { sacrotuberal largo, superfície ventral } \\
\text { da tuberosidade isquiática. }\end{array}$ & $\begin{array}{l}\text { Epicôndilo medial do fêmur e } \\
\text { tuberosidade da tíbia. }\end{array}$ & $\begin{array}{l}\text { Extensão da articulação do quadril e } \\
\text { realizar a adução do membro. }\end{array}$ \\
\hline Músculo sartório & $\begin{array}{l}\text { Fáscia ilíaca tendão do músculo } \\
\text { psoas menor }\end{array}$ & $\begin{array}{l}\text { Ligamento patelar e tuberosidade da } \\
\text { tíbia }\end{array}$ & $\begin{array}{l}\text { Flexionar a articulação do quadril e realizar } \\
\text { a adução do membro }\end{array}$ \\
\hline Músculo grácil & $\begin{array}{l}\text { Terço médio da sínfise pélvica, } \\
\text { superfície ventral do púbis. }\end{array}$ & $\begin{array}{l}\text { Superfície medial da tíbia e fáscia } \\
\text { crural. }\end{array}$ & Realizar adução do membro \\
\hline Músculo pectíneo & $\begin{array}{l}\text { Tendão pré-púbico, ligamento } \\
\text { acessório do fêmur, borda cranial do } \\
\text { púbis. }\end{array}$ & Metade da borda medial do fêmur. & $\begin{array}{l}\text { Realizar a ação do ]membro e flexionar a } \\
\text { articulação do quadril. }\end{array}$ \\
\hline Músculo adutor & $\begin{array}{l}\text { Superfície ventral do púbis e do ísquio } \\
\text { e tendão de origem do músculo grácil. }\end{array}$ & $\begin{array}{l}\text { Superfície caudal do fêmur do nível } \\
\text { do terceiro trocanter até o epicôndilo } \\
\text { medial do fêmur. }\end{array}$ & $\begin{array}{l}\text { Realizar a ação do membro e estender } \\
\text { a articulação do quadril, gira o fêmur } \\
\text { medialmente. }\end{array}$ \\
\hline Músculo reto femoral & $\begin{array}{l}\text { Duas depressões no corpo do ílio, } \\
\text { dorsal e cranial ao acetábulo. }\end{array}$ & Base da patela & $\begin{array}{l}\text { Estender a articulação do joelho e } \\
\text { flexionar a articulação do quadril. }\end{array}$ \\
\hline Músculo vasto lateral & $\begin{array}{l}\text { Borda lateral do fêmur, do trocanter } \\
\text { maior até a fossa supracondilóide. }\end{array}$ & $\begin{array}{l}\text { Parte lateral da patela, tendão do } \\
\text { músculo reto femoral. }\end{array}$ & Estender a articulação do joelho. \\
\hline Músculo vasto medial & $\begin{array}{l}\text { Superfície medial do fêmur, terço } \\
\text { proximal até o terço distal. }\end{array}$ & $\begin{array}{l}\text { Borda medial da patela, tendão do } \\
\text { músculo reto femoral. }\end{array}$ & Estender a articulação do joelho. \\
\hline Músculo vasto intermédio & $\begin{array}{l}\text { Superfície cranial do fêmur, do quarto } \\
\text { proximal ao quarto distal. }\end{array}$ & Base da patela. & $\begin{array}{l}\text { Estender a articulação do joelho, tensionar } \\
\text { a cápsula femoropatelar durante a } \\
\text { extensão da articulação. }\end{array}$ \\
\hline Músculo quadrado Profundo & Ísquio & Fossa trocantérica & $\begin{array}{l}\text { Projetar caudalmente dos membros } \\
\text { pélvicos }\end{array}$ \\
\hline Músculo piriforme & Ultima vértebra sacral & Terço proximal lateral do fêmur & Estender o quadril \\
\hline Músculo obturador Interno & Forame obturador & Fossa trocantérica & $\begin{array}{l}\text { Projetar caudalmente dos membros } \\
\text { pélvicos }\end{array}$ \\
\hline Músculos gêmeos & Espinha esquiática & Fossa trocantérica & $\begin{array}{l}\text { Rotacionar lateralmente do membro } \\
\text { pélvico }\end{array}$ \\
\hline
\end{tabular}

Quadro 1: Pontos de fixação e ação dos músculos da coxa de Tapirus terrestris. 


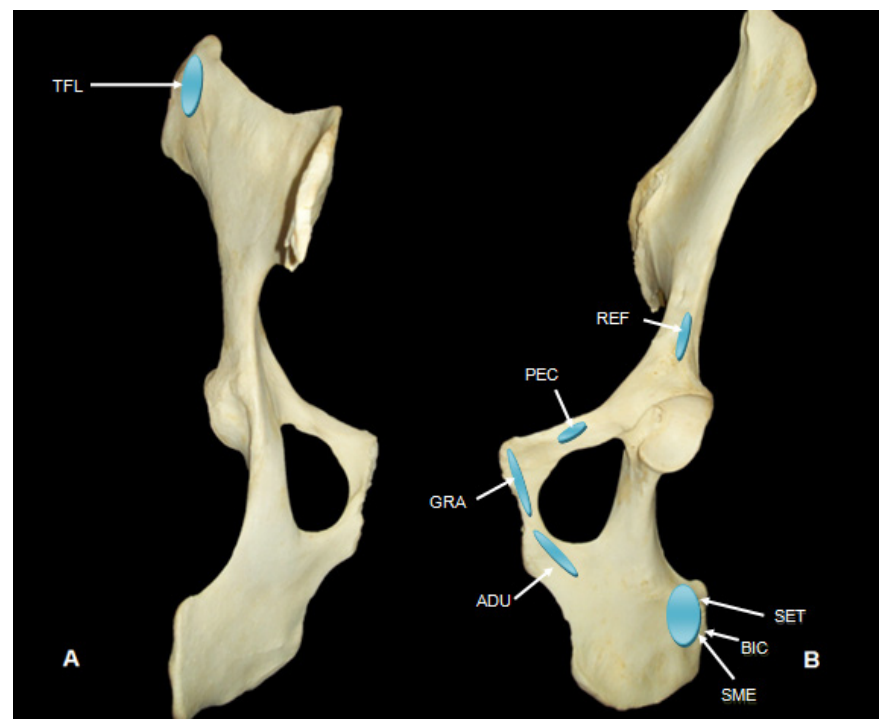

Figura 5: Fotografia dos ossos do quadril de Tapirus terrestris. Origens dos músculos da coxa. (A) vista dorsal; (B) vista ventral. SME, semimembranáceo; SET, semitendíneo; GRA, grácil, ADU, adutor; PEC, pectíneo; REF, reto femoral; TFL, tensor da fáscia lata; BIC, bíceps femoral.

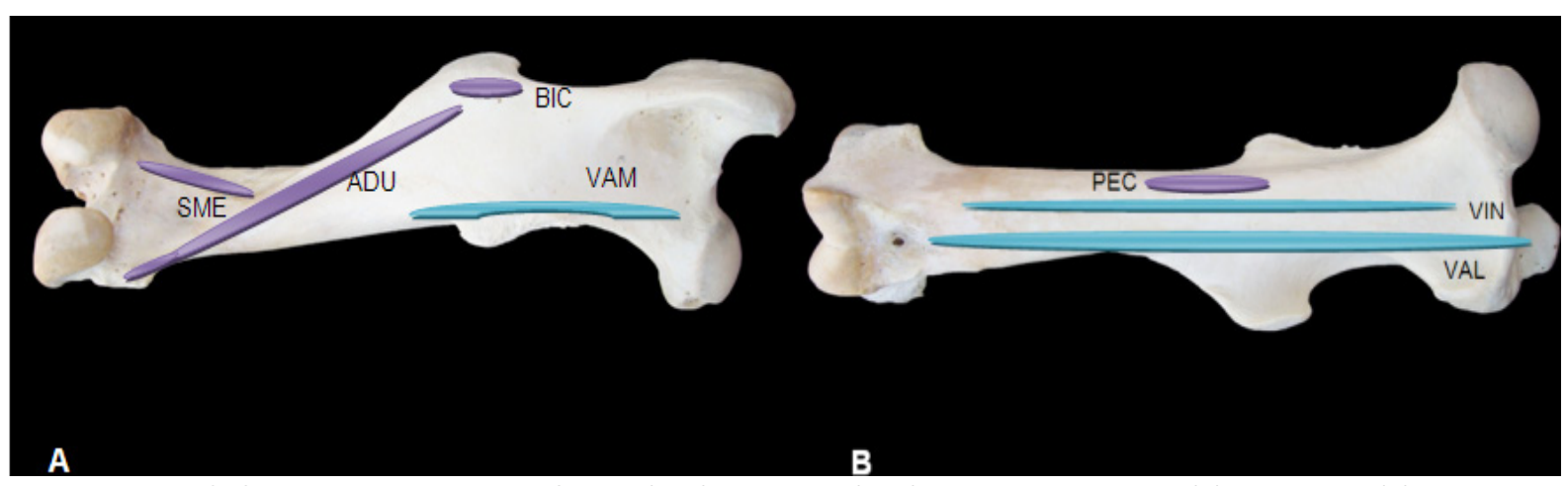

Figura 6: Fotografia fêmur de Tapirus terrestris. Origens (azul) e inserções (roxo) dos músculos da coxa. (A) vista caudal; (B) vista cranial. SME, semimembranáceo; ADU, adutor; BIC, bíceps; VAM, vasto medial; PEC, pectíneo; VIN, vasto intermédio; VAL, vasto lateral.

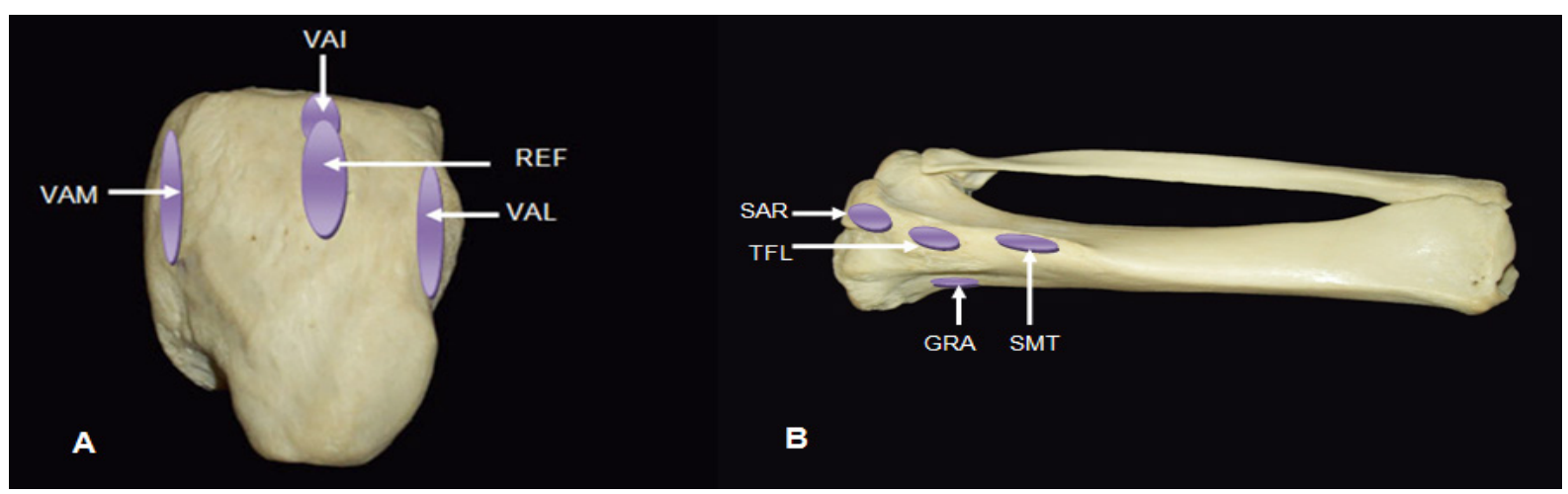

Figura 7: Fotografia patela, tíbia e fíbula de Tapirus terrestris. Inserções dos músculos da coxa. (A), vista cranial da patela; (B), Vista cranial tíbia e fíbula. VAM, vasto medial; VAI, vasto intermédio; REF, reto femoral; Val, vasto lateral; SAR, sartório; TFL, tensor da fáscia lata; GRA, grácil; SMT, semitendíneo. 
O músculo bíceps femoral é muito desenvolvido e segundo Konig e Liebich, (2016) distalmente esse músculo apresenta duas expansões nos carnívoros, suínos e ruminantes, e três expansões nos equinos, apresentando também essas três expansões em T. terrestris. Segundo Getty (2013), o músculo bíceps femoral no equino tem sua origem nos ligamentos sacroilíacos, as fáscias glúteas e da cauda e tuberosidade isquiática com inserção na superfície caudal do fêmur, superfície cranial da patela, borda cranial da tíbia, fáscia crural e tuberosidade calcânea como verificado na espécie estudada (Quadro 1), sendo assim pode-se sugerir que devido às origens e inserções serem bastante semelhantes o músculo exerce movimentos semelhantes aos exercidos nos equinos, fato corroborado pelas ilustrações de Konig e Liebich, (2016).

O músculo tensor da fáscia lata situa-se na porção cranial e tem formato triangular (Figura 4), segundo Getty (2013) nos equinos esse músculo tem a sua origem na tuberosidade da coxa seguindo até a fáscia lata que indiretamente se liga a patela e borda cranial da tíbia. Em T. terrestris tal músculo tem o mesmo ponto de origem, porém o ponto de inserção se difere sutilmente, pois o mesmo insere-se na fáscia lata que se liga a patela e ao tendão do músculo reto femoral ligando-se a tíbia (Quadro 1).

O músculo semitendíneo forma o contorno caudal da coxa, segundo Konig e Liebich, (2016), no suíno e no equino o mesmo se origina na tuberosidade isquiática e nos processos espinhosos e transversais do sacro e das primeiras vértebras caudais, Getty (2013) ainda complementa uma origem no septo intermuscular entre tal músculo e o bíceps femoral que é encontrada em $T$. terrestris (Figura 4), evidenciando que o músculo possui função e movimento semelhante ao dos equinos.

O músculo semimembranáceo em $T$. terrestris é um músculo longo que se relaciona lateralmente com o músculo grácil, cranialmente com os músculos adutores e sartório e caudalmente com o músculo semitendíneo. Pereira; Lima; Pereira (2010) descreveram o músculo semimembranáceo em Procyon cancrivorus - Cuvier, 1798 (mão-pelada) como tendo sua origem na tuberosidade isquiática e inserção no epicôndilo medial do fêmur e epicôndilo medial da tíbia já em $T$. terrestris ele tem origem no ligamento sacrotuberal e tuberosidade isquiática e inserção na borda lateral e epicôndilo medial do fêmur e tuberosidade da tíbia. Apesar do músculo em T. terrestris apresentar pequenas distinções na origem e inserção em comparação $P$. cancrivorus apresentam a mesma função que é estender a articulação do quadril e abduzir o membro pelvino conforme o quadro 1.

O músculo sartório situa-se superficialmente na vista medial da coxa sendo um músculo fino e estreito (Figura 4). Segundo Konig e Liebich, (2016) nos ruminantes o músculo forma em sua origem duas cabeças, já nos equinos o mesmo origina-se no tendão do músculo psoas menor e fáscia ilíaca, em T. terrestris o músculo sartório origina-se no tendão do músculo psoas menor, relacionando-se medialmente com o fêmur, cranialmente com os músculos grácil e caudalmente com o músculo vasto medial unindo-se ao ligamento patelar medial e ligando-se a tuberosidade da tíbia. Portanto o músculo sartório em T. terrestris tem sua origem e inserção muito semelhante aos equinos como citado pelo autor, levando a crer que possua função similar no processo de locomoção da espécie.
O músculo grácil é um músculo longo, largo e quadrilátero que se situa caudalmente ao músculo sartório e cobre uma grande parte da superfície medial da coxa (Figura 4) como ilustrado por Schaller (1999). Ele contribui para a formação dos componentes caudais que compõe a superfície medial da coxa, possuindo a mesma origem e inserção apresentada pelos equinos.

O músculo pectíneo possui aspecto fusiforme. De acordo com Getty (2013) e Konig e Liebich, (2016) no equino o músculo pectíneo se estende desde a margem cranial do púbis e a eminência iliopúbica, com sua origem no tendão pré-púbico, ligamento acessório do fêmur e borda cranial do púbis situando-se entre o músculo adutor e vasto medial também observado pelos estudos de Pereira; Lima; Pereira (2010) o que corresponde aos achados em $T$. terrestris como amostrados nas Figuras 6 e 7.

Segundo Konig e Liebich, (2016) e Getty (2013) o músculo adutor nos equinos é constituído de um grupo de músculos que são separados em músculo adutor curto e músculo adutor magno situando-se entre os músculos pectíneo e semimembranáceo, já no cão e no gato existe apenas um adutor longo o que também se evidencia em $T$. terrestris, onde há apenas um músculo adutor que se situa na mesma posição do equino, entre o músculo pectíneo e semimembranáceo (Figura 4).

O músculo quadríceps femoral em $T$. terrestris é constituído pelos músculos reto femoral, vasto lateral, vasto medial e vasto intermédio e situam-se na face medial, lateral e cranial da coxa. Três cabeças originam-se no fêmur e uma delas origina-se no ílio conforme apresentado no quadro 1 , sendo essa origem mantida em todos os animais domésticos como relatado por Konig e Liebich (2016). O músculo reto femoral é a porção mais longa e a única que se origina no osso pelvino por duas depressões no corpo do ílio. O músculo vasto lateral se origina na superfície lateral do fêmur e o vasto medial na superfície medial encontrando-se encoberto pela fáscia lata. Caudalmente ao músculo reto femoral se encontra o músculo vasto intermédio. A origem e inserção desses músculos ocorrem de forma similar ao equino, portanto, sugere-se que os músculos possuam a mesma função.

O músculo piriforme fusciona-se ao músculo glúteo médio em T. terrestris. Localizando-se caudalmente a este. Sua origem é na ultima vértebra sacral e insere-se na face lateral no fêmur em seu terço proximal.

O músculo quadrado profundo de T. terrestris, assim como os de equinos é um pequeno e fino músculo que se alonga na face ventral da pelve até a fossa trocantérica. O músculo obturador interno origina-se no forame obturado insere-se na fossa trocantérica e tem a função de auxiliar na rotação do membro pélvico como em equinos e ruminantes (KÖNIG, LIEBICH, 2016). Os músculos gêmeos estão pouco evidentes e estão aparentemente fusionados, tem sua origem junto à espinha esquiática e sua inserção na fossa troncatérica. Sua função aparente devido sua localização e auxiliar na rotação lateral do membro pélvico.

\section{Conclusão}

A partir dos resultados, foi possível concluir que o esqueleto do cíngulo pélvico de $T$. terrestris era constituído pelo osso do quadril, formado pelos ossos isquio, ílio e púbis. A coxa era 
constituída pelo osso fêmur e na região da articulação do joelho encontra-se a patela. As antas apresentaram características osteológicas do cíngulo pélvico e coxa semelhantes a outros perissodactilos, com os quais foram relacionados por uma maior proximidade taxonômica. Entretanto, algumas diferenças

\section{Referências}

BORGES, D.C.S. SANTOS, A.L.Q; PEREIRA, S.G.; PEREIRA, W.A.; PEREIRA, R.A. Características adaptativas do membro pelvino de Tapirus terrestris (Perissodactyla, Taperidae). ALTUS CIÊNCIA: Revista Acadêmica Multidisciplinar da Faculdade Cidade de João Pinheiro. IV, vol. 04. 05-15. 2016

GETTY, R. Anatomia dos animais domésticos. $5^{\text {a }}$ Edição. Rio de Janeiro: Ed Guanabara Koogan. 2013. 2000 p.

HICKMAN JR., C.P.; ROBERTS, L.S.; LARSON, A. Princípios Integrados de Zoologia, $11^{a}$ ed., Rio de Janeiro: Ed. Guanabara Kogan, 2009, 846pg.

HOLANDA, E.C. FERIGOLO, J. RIBEIRO, A.M

New Tapirus species (Mammalia: Perissodactyla: Tapiridae) from the upper Pleistocene of Amazonia, Brazil. Journal of Mammalogy. v. 92, n. 10, p. 111-20. fev. 2011.

INTERNATIONAL COMMITTEE ON VETERINARY GROSS ANATOMICAL NOMENCLATURE. Nomina anatomica veterinária. 2012. 5. ed. (rev.) Knoxville: World Association on Veterinary Anatomist. $177 \mathrm{p}$

KÖNIG, H. E.; LIEBICH, H.G. Anatomia dos animais domésticos: texto e atlas colorido. 6. Ed. Porto Alegre: Artmed, 2016.

MEDICI, E.P. Family Tapiridae (Tapirs). In: WILSON, D.E; MITTERMEIER, R,A. Handbook of the mammals of the worldVolume 2: Hoofed Mammals. Barcelona: Lynx Edicions; 2011. $886 \mathrm{p}$.

OLIVEIRA, F.S.; CANOLA, J.C.; MACHADO, M.R.F.; CAMARGO, M.H.B. Descrição anátomo-radiográfica do esqueleto apendicular da paca (Agouti paca). Acta Scientiae Veterinariae. v. 35. n. 1. 83-87, 2007.

OLIVEIRA, F.S.; MARTINS, L.L.; PAULONI, A.P.; TONIOLLO, G.H.; CANOLA, J.C.; MACHADO, M.R.F. Descrição anátomoradiográfica do esqueleto apendicular da cutia (Dasyprocta azarae, Lichtenstein, 1823). Ars veterinária, Jaboticabal, v. $25, \mathrm{n}$. 1, p. 28-31, 2009. morfológicas foram evidenciadas. Os músculos tem sua origem no osso do quadril seguem um padrão semelhante a outros perissodáctilos. São músculos que auxiliam no padrão de locomoção dessa espécie para força, e movimentos em geral de um animal cursorial.

PADILLA M; DOWLER R.C. Tapirus terrestris. Mammalian Species. Dec 2;(481):1-8. 1994

PEREIRA, F.C.; LIMA, V.M.; PEREIRA, K. F. Morfologia dos músculos da coxa de mão-pelada (Procyon cancrivorus) - cuvier 1798. Ci. Anim. Bras., Goiânia, v. 11, n. 4, p. 947-954, out./dez. 2010

PEREIRA, S.G. SANTOS, A.L.Q. BORGES, D.C.S. RIBEIRO, P.R.Q.; RODRIGUES, R. Anatomia Óssea E Muscular Do Cíngulo Escapular E Braço De Tapirus terrestris (Perissodactyla: Tapiridae). Ciênc. anim. bras. Goiania. vol.16. n.2 . 2015

PEREIRA, S.G; BORGES, D.C.S. SANTOS, A.L.Q. Aspectos histológicos dos músculos da região da escápula e do braço de anta - Tapirus terrestris - Perisodactyla, Tapiridae. Revista Acadêmica: Ciência Animal, [S.I.], v. 15, p. 1-6, maio 2017.

PEREIRA, S.G. SANTOS, A.L.Q.; BORGES, D.C.S; SOUZA, R.R.; RIBEIRO, P.R.Q. Anatomia óssea e muscular do antebraço e mão de Tapirus terrestris (Perissodactyla, Tapiridae). Biotemas, Florianópolis, v. 30, n. 2, p. 35-41, maio 2017.

RIBEIRO, P.R.Q.; SANTOS, A.LQ.; RIBEIRO, L.A,; SOUZA, T.A.M.; BORGES, D.C.S.;SOUZA, R.R.; PEREIRA, S.G. Movement anatomy of the gluteal region and thigh of the giant anteater Myrmecophaga tridactyla (Myrmecophagidae: Pilosa). Pesq. Vet. Bras. vol.36 no.6 Rio de Janeiro June 2016

SALAS, L.A.; FULLER, T.K. Diet of the lowland tapir (Tapirus terrestris L.) in the Tabaro River valley, southern Venezuela. Canadian Journal of Zoology, 74: 1444-1451. 1996.

SCHALLER, O.; Nomenclatura Anatômica Veterinária Ilustrada. São Paulo. Ed. Manole. 1999. 614p.

SCHWARZE, E. SCHRÖDER, L. Compendio de anatomia veterinária aparelho locomotor. Zaragoza: Acribia, 1970. V1. $318 p$.

VARELA, G. Osteología y miología de lós miembros anterior e posterior del venado de campo (Ozotoceros bezoarticus). 2010. $51 \mathrm{f}$. Tesina (Licenciatura en Ciencias Biológicas) - Universidad de La República Uruguay, Uruguay, 2010. 